\title{
TIDE-TSUNAMI INTERACTION IN A HIGHLY ENERGETIC CHANNEL. A CASE STUDY.
}

\author{
Patricio Winckler, Universidad de Valparaíso. Chile. \\ Ignacio Sepúlveda, Cornell University. United States. \\ Felipe Aron, Pontificia Universidad Católica de Chile. Chile. \\ Manuel Contreras-López, Universidad de Playa Ancha. Chile.
}

\begin{abstract}
INTRODUCTION
Tsunami-tide interaction can be assessed using different approaches with increasing levels of complexity. The simplest is to compute the sea level through a linear superposition of the tide and the tsunami computed independently (composite model). Recent studies have found that composite models provide inaccurate results in shallow waters (e.g. Kowalik et al, 2010). A more realistic analysis is achieved by computing the tsunami and the tide together (full model). This approach is appropriate where nonlinear effects may be important due to strong tides or shallow bathymetries. This work is intended to improve the physical understanding of tidetsunami interaction in Canal Chacao, a highly energetic channel sited in Chile. This channel is dominated by currents of up to $6[\mathrm{~m} / \mathrm{s}$ ] during spring tide and is located in a region prone to tsunamis. The fundamental question is to assess under which conditions tides and tsunamis can be linearly superposed and in which they interact nonlinearly, thus enhancing or reducing the surface elevation and associated currents.
\end{abstract}

\section{MODELING SETUP}

Simulations for the composite and full models were implemented using a 2D model based on the nonlinear shallow-water wave equations on a flexible mesh. A model for tsunami with constant tide equal to the mean sea level (pure tsunami model) was also implemented. Tide is included via 11 major diurnal, semidiurnal and other constituents, specified in additional terms in the momentum equations using a global tide model. Tides are ramped for 2 days until a dynamic equilibrium is reached. Calibration with tide gauges is performed within the Canal Chacao for 28 days, covering one tidal cycle. Correlations between measured and modeled tide elevations in various sites range between $91 \%$ and $96 \%$ while a correlation of $73 \%$ is achieved with ADCP data at the center of the channel. A Mw 9.51960 typeearthquake based on Fujii and Satake's (2013) inversion model is used to trigger the vertical seafloor deformation using Okada's (1992) theory. This deformation is corrected for the topographic slope of the subduction slab. The tsunami is triggered every two hours within a 12 hours tide cycle for both the composite and full models, resulting in a set of 6 models for each model strategy,, as depicted in Figure 1 (e.g. F1921 stands for a model starting on February 19 at 21:00). These dates are chosen to cover the spring tide since nonlinear interactions are expected to be enhanced.

\section{RESULTS AND DISCUSSION}

Time series of elevation for the pure tsunami, composite and full models in a station at the center of Canal Chacao are depicted in Figure 1. Only the first 3.5 hours of simulation are depicted, since the tsunami signal is attenuated afterwards. Time series initiate at the moment of the earthquake to facilitate comparison. In general, it is observed that the hydrodynamic patterns obtained with the three models differ significantly, being the linear and nonlinear models very sensitive to the tide level at the time of the tsunami attack. The elevation at $\mathrm{t}=0$ is negative due to the subsidence triggered by the earthquake in the station. Larger (smaller) maximum (minimum) elevations are found with the nonlinear model; their occurrence not necessarily associated to the first wave as a consequence of the varying tide. Maximum velocities (not shown) are found with the composite model; being roughly $25 \%$ larger than the full model. This result has important consequences on drag forces and sediment transport. Finally, the full model better captures the advance (or delay) of the first wave due to the interaction between the current flood tide (ebb tide) and the tsunami, so it is recommended for warning systems. The disparity of results between composite and full models are due to nonlinear interactions, the influence of the total water depth, the role of the bottom friction and the distortions of long waves when they propagate from the continental shelf onto shallower coastal waters. So far, the individual contribution of these effects has not been analyzed. The outcomes of our research are essential for improving tsunami hazard assessments in semi-enclosed water bodies with significant tidal ranges.

\section{REFERENCES}

Kowalik et al. (2006). Tide-tsunami interactions. Sci. Tsunami Hazards 24 (4), 242-256.

Okada (1992), Internal deformation due to shear and tensile faults in a half-space, Bull. Seismol. Soc. Am., 82(2), 1018-1040.

Fujii and Satake (2013), Slip Distribution and Seismic Moment of the 2010 and 1960 Chilean Earthquakes Inferred from Tsunami Waveforms and Coastal Geodetic Data, Pure Appl. Geophys., 170(9-10),
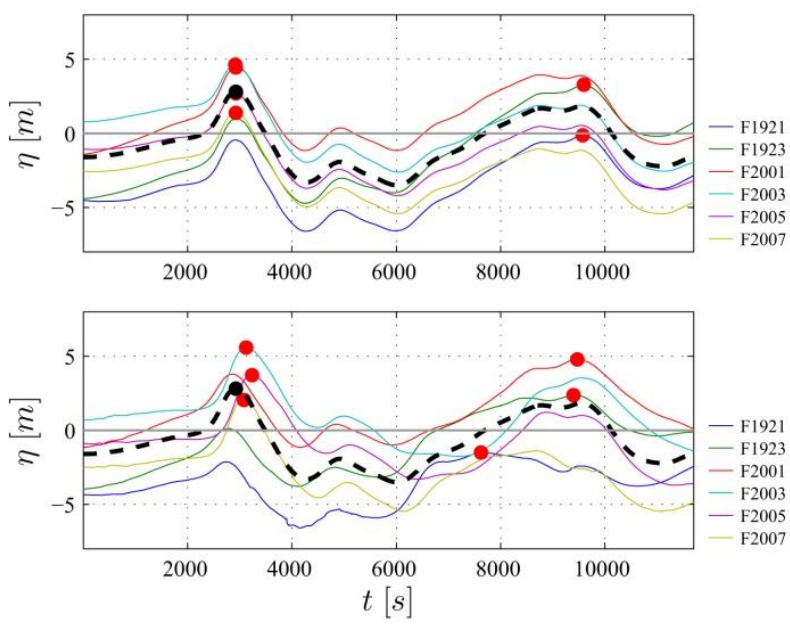

Figure 1: Surface elevation at six different initiation times for the composite model (upper panel) and full model (lower panel). The pure tsunami model is depicted in black segmented lines. 